\title{
Johnson, MacIntyre, and the Practice of Argumentation
}

\section{TONE KVERNBEKK}

University of Oslo

Institute of Educational Research

PO Box 1092 Blindern

$\mathrm{N}-0317$ Oslo

Norway

tone.kvernbekk@ped.uio.no

\begin{abstract}
This article is a discussion of Ralph Johnson's concept of practice of argumentation. Such practice is characterized by three properties: (1) It is teleological, (2) it is dialectical, and (3) it is manifestly rational. I argue that Johnson's preferred definition of practice-which is Alasdair MacIntyre's concept of practice as a human activity with internal goods accessible through partcipation in that same activity-does not fit these properties or features. I also suggest that this failure should not require Johnson to adjust the properties to make them fit the practice concept. While MacIntyre's concept of practice clearly has some attractive features, it does not provide what Johnson wants from a concept of practice.
\end{abstract}

Resumé: Dans cet article on discute du concept de la pratique d'argumentation avancée par Ralph Johnson. Une telle pratique a trois propriétés : elle est téléologique, dialectique, et manifestement rationnelle. Mais la définition préférée de Johnson de la pratique-conçue par Alasdair MacIntyre comme une activité avec des biens internes accessibles en y participant-ne s'accorde pas bien avec ces propriétés. Je suggère que cette faiblesse n'oblige pas Johnson à ajuster ces propriétés à son concept de pratique. Quoique le concept de pratique de MacIntyre a évidemment quelques traits attrayants, il n'offre pas ce que Johnson veut d'un concept de pratique.

Keywords: Argumentation practice, features/properties, internal goods, Johnson, MacIntyre, poiesis, practice, purposive practice, teleology

\section{Introduction}

The concept of practice is widely employed in many different fields and professions, with varying degrees of clarity and explicitness. In his book Manifest Rationality (2000), Ralph Johnson defines the practice of argumentation as follows: "By "the practice of argumentation” I understand the sociocultural activity of constructing, presenting, interpreting, criticizing, and revising arguments" (2000, p. 12). The various forms of such practice can be characterized by three properties or features: (1) It is 
teleological; (2) it is dialectical; and (3) it is manifestly rational; all of which will be explained below. I shall not inquire into whether these are or should be the (most) salient features of the practice of argumentation, or whether taken together they cover all or most examples of argumentation practice. Rather, I shall investigate the degree to which Johnson's preferred definition of the concept of practice actually accommodates these features. Johnson employs Alasdair MacIntyre's (1996) definition of practice, and describes his own understanding as coming "quite close” to MacIntyre's (2000, p. 155). The question then is just how close it is. I shall argue that MacIntyre's concept of practice, which is highly complex, abstract and widely used, does not provide Johnson with what he wants from a concept of practice.

Does it matter what concept of practice we employ? I think it does. Our understanding of 'practice' will have an impact on how we perceive our own (professional) roles and tasks, especially if our concept is a complex one that comprises more than just actions. Further, it will have an impact on how we view and conceptualize the theory-practice relationship. What we take the practice of argumentation to be is also of some significance for what we think a theory of such practice should be. This last point is certainly important to Johnson, who not only sees argumentation theory as the study of the practice of argumentation (p. 30), but also claims that "...the normative dimension of the theory of argument (what I call the theory of appraisal) must develop out of a proper understanding of the practice of argumentation...” (p. 6).

It is, however, not my business in this paper to discuss possible consequences of a MacIntyrean understanding of practice for Johnson's overall theory of argumentation. Rather, it is my intention to analyze the concept of practice in some detail to show why I think that MacIntyre's concept of practice does not satisfy the three features of argumentation practice suggested by Johnson, and thus is unsuited for building an adequate concept of argumentation practice. I will do this by, among other things, juxtaposing the practice of argumentation with the practice of teaching. There are some reasons for this. The adequacy of MacIntyre's concept of practice is hotly debated in the education field, and there might be insights to be gleaned from this extensive discussion. Furthermore, MacIntyre himself states that teaching is not a practice, and his reasons for this are illuminating.

First, I shall present Johnson's description of argumentation practice. Second, I shall juxtapose MacIntyre's concept of practice with the practice of argumentation such as it has been laid out, drawing on discussions of the practice of teaching as I go along. My analysis is structured around the notions of internal goods, teleology and poiesis. The first two of these belong to MacIntyre's concept of practice, and the third is included both because it 
provides an interesting contrast to practice, and because it helps bolster my argument that MacIntyre's 'practice' does not accommodate the features of argumentation practice. All three will be explained subsequently. Admittedly, my analysis does not address Johnson's reasons for adopting MacIntyre's concept of practice in the first place, or why a concept of practice became central to the development of Johnson's theory of argumentation.

\section{Johnson's characterization of the practice of argumentation}

Before I embark on my presentation of Johnson's views, a few things need to be said about definitions and levels of abstraction. Johnson, as we have seen, defines the practice of argumentation as "the sociocultural activity of constructing, presenting, interpreting, criticizing, and revising arguments" (2000, p. 12). David Hitchcock takes that definition as the point of departure in his discussion of Johnson's concept of argumentation practice (Hitchcock 2002). Hitchcock's incisive analysis takes a different route than the one I propose to take. He argues that Johnson's definition "presupposes that there is exactly one sociocultural activity, perhaps occurring at many times and places, which incorporates the dimensions mentioned in a single whole" (2002, p. 287), and then digs into the content of the definition in some detail. He problematizes the definition in terms of what falls under the concept, as Johnson uses it, and what falls outside it. He also proposes a modified definition of argumentative discussion that distinguishes it from more rhetorically driven practices. Generally, but with some alterations and modifications, Hitchcock endorses Johnson's thinking.

My business in this article is not to discuss the specific content of the concept of argumentation practice. The definition above is quite specific in its mention of certain acts; construct, present, interpret, criticize, revise. But the three properties said to be characteristic of a practice comprising such acts themselves make no mention of specific acts. They are derived from detailed analyses and are located at a higher level of abstraction. MacIntyre's definition of practice is also abstract; it makes no mention of specific acts or actors. And since my aim in this article is to inquire into the adequacy of MacIntyre's concept of practice for Johnson's theory, it seems a more sensible strategy for me to keep my main focus on the three properties. My presentation of them here will include just enough detail to show why Johnson views them as characteristic of the practice of argumentation.

I begin my presentation by citing Johnson's conclusion, which is as follows, 
Because argumentation is a teleological practice that aims at rational persuasion, it must be dialectical; because argumentation is both rational and dialectical, it must be manifestly rational (2000, p. 164).

The road leading up to this conclusion begins with situating argumentation as a cultural practice. The practice of argumentation is, as we have seen, a "sociocultural activity of constructing, presenting, interpreting, criticizing, and revising arguments” (p. 12). Such an activity must be understood as broadly cultural; it takes place within the network of customs, ideas, habits and activities of society. The practice of argumentation, according to Johnson (p. 13), comprises four basic "elements"; the process, the arguer, the other, and the product which is the argument. Naturally these elements cover a multitude of activities and persons, etc.; and as a whole, as an enterprise, practice has three basic features, given in the conclusion above.

The first feature or property of the practice of argumentation is teleology. By describing argumentation practice as teleological, Johnson simply means that it is goal-directed. Ordinarily 'teleology' indicates phenomena which exhibit order, design, purposes, ends, tendencies or direction, but Johnson does not endow his use of the word with any metaphysical assumptions. The teleological character of argumentation means that it helps us achieve many different goals, among them rational persuasion, inquiry, decision-making and justification. It is Johnson's overall pragmatic approach that makes it reasonable to construe teleology as the first of the three properties, because such an approach begins by inquiring after the purpose of a given activity. And while, as we have seen, argumentation serves many purposes, there is one that stands out: "But pre-eminent among them is the function of persuading someone [...] of the truth of something [...] by reasoning, by producing a set of reasons whose function is to lead that person rationally to accept the claim in question” (p. 149).

This formulation of the telos of argumentation points in two directions: to a set of reasons or evidence for the claim-the illative core of the argument, the first tier-and to a recipient of the argument; an Other. Arguments may consist of the first tier only; that is, they present reasons or premises to support a conclusion. Johnson discusses in some detail several criteria for evaluation of the illative core of an argument ( p. 190f). But some arguments have two tiers, and those are the ones that interest us here. A second tier, the dialectical tier, is required because the arguer's purpose is rational persuasion. The Others should not be easily won over to the arguer's point of view, they may argue back: "If the arguer does not deal with the objections and criticisms, then to a degree, the argument is not going to satisfy the dictates of 
rationality" (p. 160). This does not imply that there will always be at least two people present, but that the arguer deals with objections and criticisms that may already be well known, or can be anticipated. A process of arguing, Johnson points out, is a type of exchange that has its own mode of temporality; it can go on for ages. Such processes also include by their very nature responses from other arguers. In principle, any arguer agrees to take feedback and criticism and treat it seriously:

If (as is likely) the arguer now modifies that argument as a result of the intervention by the Other, the result is an improved product-a better argument. The intervention of the Other is thereby seen to lead to the improvement of the product. It has become a better argument, a more rational product (p. 161).

Just as for the illative core, there is a discussion about various criteria for the dialectical tier (p. 206f).

An argument is minimally an exercise in rationality. Argumentation depends on rationality; exhibits it and increases it. In the opening pages of his book Johnson preliminarily specifies rationality as the ability to give and receive reasons, and he sticks with this understanding of it: “ $\ldots$ rationality can be understood as the disposition to, and the action of, using, giving, and/or acting on the basis of reasons" (p. 161). All of Johnson's proposed practice properties are closely interconnected. The telos of argumentation, rational persuasion, implies the giving of reasons and the handling of objections and criticisms. The rational and the dialectical features reinforce each other. Taken together, they point to the third feature; manifest rationality. Argumentation is bound by the requirement of manifest rationality. This means that it is patently and openly rational to all participants, whether they be arguers, critics or merely an interested public. The requirement of manifest rationality, Johnson says, makes argumentation something more than just an exercise in rationality. It is the reason why arguers are obligated to respond to objections, regardless of whether they are misguided or not, and not ignore them. As Johnson puts it,

It is not just that to do so [i.e., ignore objections] would not be rational or would not be in keeping with the spirit of the practice. It is that it would be an obvious violation of it-and it would be seen to be such. Thus, to put the matter somewhat strangely, it would not only not be rational; it would not look rational (p. 164, emphasis original). 
With this we have reached the conclusion with which I began my account; namely Johnson's view that his selected features are intimately related. Argumentation practice must be dialectical because its telos is rational persuasion, and because it is dialectical and rational, it must be manifestly rational. Responses to and criticisms of arguments have the same telos, Johnson argues, and should proceed along the same principles as those guiding the arguer:

... argumentation as a practice is characterized by three features: (a) it is teleological; (b) it is dialectical; (c) it is manifestly rational. If criticism is to be part of this practice, then it too must exhibit the same features (Johnson, 2000, p. 222).

Admittedly, my order of presentation does not reflect the degree of importance Johnson attaches to the properties. For him, manifest rationality is particularly important, since other practices or activities may be both teleological and dialectical, whereas manifest rationality is a particular feature of argumentation. Still, all three taken together are needed to "sum up" and portray the practice of argumentation. It is now time to juxtapose this portrayal with the concept of practice.

\section{Macintyre's practice and argumentation practice}

Alasdair MacIntyre's (1996, first published 1981) definition of practice has over the years been very attractive to both academics and practitioners, not least in the field of education. Part of its power of attraction, one might speculate, lies in its being a single, overall, holistic concept. Such definitions may help to keep large, untidy and fragmented fields together, and they may prevent less abstract attempts at definition from highlighting one aspect of a field at the expense of others. Here is MacIntyre's definition of practice:

By a 'practice' I am going to mean any coherent and complex form of socially established cooperative human activity through which goods internal to that form of activity are realized in the course of trying to achieve those standards of excellence which are appropriate to, and partially definitive of, that form of activity, with the result that human powers to achieve excellence, and human conceptions of the ends and goods involved, are systematically extended (MacIntyre 1996, p. 187). 
In the context of argumentation, as Johnson points out, the activity in question is the activity of constructing and responding to arguments. Moreover, Johnson says, "The goods internal to that activity are generally an increase in rationality and specifically a deeper understanding, and/or being rationally persuaded, and/or coming closer to an acceptable position” (2000, p. 155). As indicated in the previous section, the standards of excellence definitive of that activity are discussed at length by Johnson. Admittedly, this concept of practice appears to fit argumentation very well indeed. And to some extent it does. But not quite.

By his own admission, MacIntyre defines 'practice' in a specific way not quite in agreement with ordinary usage (including his own previous use of the word). The reason for this is that it serves a particular purpose in his socially teleological account of the nature of the virtues. The motivation for such an account of virtues is his overall diagnosis of the social world: that it is fragmented, that the language of morality has fallen into disorder, and that emotivism rules the day. Emotivism is the doctrine that all judgments, including all moral judgments “... are nothing but expressions of preference, expressions of attitude or feeling, insofar as they are moral or evaluative in character" (1996, p. 12, emphasis original). MacIntyre thus has a moral agenda. He criticizes liberalism and the Enlightenment, and as Christopher Higgins (2003) points out, his solution is to return to Aristotle. The concept of practice is part of MacIntyre's proposed solution.

So MacIntyre turns to Aristotle in his combat against fragmentation of both the social world and the self. The point of departure is the concept of virtue and the idea of a good life. The concept of virtue, he argues, requires for its application a rich background consisting of both social and moral theory; which of course makes for a highly complex discussion. The logical development of the concept of a virtue takes place in three stages, each with their own conceptual backgrounds. These three stages he calls practice, narrative order of a single human life, and (moral) tradition. The stages portray the history of the long tradition of which virtue forms the core. Practice is the first of these stages. Hence his special way of defining the concept of practice. It provides ".. the arena in which the virtues are exhibited and in terms of which they are to receive their primary, if incomplete, definition...” (MacIntyre 1996, p. 187).

The range of such practices is wide. Falling under the concept are, for instance, arts, sciences, games and the making of family life. According to MacIntyre painting is a fairly prototypical example of a practice. On the other hand, he explicitly denies that teaching is a practice (MacIntyre \& Dunne 2002). So the departure point for our investigation here will be whether argumentation is more like painting or more like teaching. 


\section{Internal goods}

In his explanation of why painting is a practice, MacIntyre focuses on the notion of goods. There are two kinds of goods one can gain by painting. First there are goods externally and arbitrarily attached to any practice by the accidents of social circumstance; such as candy, prestige or money. More importantly, however, there are goods that are internal to the practice of painting; goods which cannot be had in any other way than by painting. Internal goods are unspecifiable apart from the practice in question, and they are only identifiable and accessible by participation in the practice. Says MacIntyre, "Those who lack the relevant experience are incompetent thereby as judges of internal goods” (1996, p. 189). There are at least two different kinds of goods internal to painting. The first also introduces excellence, which is integral to his concept of practice. There is the excellence of the product, say a portrait, and the excellence in the performance by the painter. Excellence must be understood historically, since standards may change and develop over time. The second kind of internal good is found precisely in the painters' endeavors to sustain progress and respond creatively to perceived problems; namely the good of a certain kind of life, the painter's living out his or her life as a painter. And again, judgments of such internal goods are the privilege of the participants in the practice.

Standards of excellence demand obedience. Upon entering a practice we accept the authority of those standards. Practices have a history, a tradition, and we become initiated into them by submitting our own performances to be judged by the best standards realized so far. This feature of practices, MacIntyre says, rules out all subjectivist and emotivist judgments of the quality of products and performances.

And, in passing, where do virtues enter the picture? A virtue is defined by MacIntyre as "an acquired human quality the possession and exercise of which tends to enable us to achieve those goods which are internal to practices and the lack of which effectively prevents us from achieving any such goods" ( p. 191).

Thus far I would suggest that the concept of practice agrees well with Johnson's rendering of argumentation. So let us look at teaching. MacIntyre's definition has led a good many teacher educators and philosophers of education to see teaching as a practice. Yet MacIntyre himself claims that teaching is a set of skills and habits put to the service of a variety of practices (MacIntyre \& Dunne 2002). Teaching is an inescapable ingredient in every practice, but is not itself a practice. His explanation for why this is so is worth quoting in full: 
For it is part of my claim that teaching is never more than a means, that it has no point and purpose except for the point and purpose of the activities to which it introduces students. All teaching is for the sake of something else and so teaching does not have its own goods (MacIntyre \& Dunne 2002, p. 9).

In other words, the goods that the teacher's job furthers are those of the subject he or she teaches. The life of a teacher, MacIntyre claims, is not a specific kind of life like that of the painter. The life of a painter is one thing; the life of a teacher of painting whose goods are the goods of painting is another. Predictably, this view of teaching has drawn a lot of critical responses from educational thinkers (e.g., Dunne 2003, Hogan 2003, Noddings 2003). These responses share a basic form: they embrace the concept of practice, but criticize MacIntyre's view of teaching for being simplistic and impoverished, and argue instead that teaching is a practice with its own internal goods and its own integrity. Then there are those who agree with MacIntyre, at least on this score. Kenneth Wain (2003) is one of them. It would be tragic, he says, if teaching was a self-serving and self-regarding profession. Teaching is a means since the good it serves is not intrinsic to itself but is the good of learner and community.

Who are the internal goods for? Higgins's thorough discussion of the concept of internal goods suggests to me that this concept may be more difficult than it appears (Higgins 2003). Internal goods mainly belong to the practitioner, he suggests, for instance as excellences of character and a meaningful, unitary life. So the practice of teaching, Higgins maintains, must be understood in terms of its role in the teachers' quest to flourish.

And here we have the main reason why I do not think that argumentation is a practice in MacIntyre's sense. While the notion of internal goods may capture a number of important things about an activity, the same notion makes a practice close in on itself and become inward-looking. As Wain and Higgins point out, the internal goods are for one's own sake. And this is precisely why MacIntyre insists that teaching is not a practice-teaching is for the sake of something else. If argumentation is a practice, then arguers argue for the sake of arguing, for the sake of perfecting an argument, for the sake of satisfying the standards of excellence. But this is not what Johnson envisions for argumentation. For Johnson explicitly states that, "The practice does not exist for itself but rather because it yields a product of value to human society" (2000, p. 209). This is part of Johnson's idea of the telos of argumentation. 


\section{Teleology}

Still, things may be a little more complicated, because MacIntyre also speaks of teleology. It is not an explicit part of his definition of practice, but it is part of the conceptual background for the virtues. Indeed, his whole account of the virtues is teleological. He calls it a socially teleological account, one that does not require Aristotle's metaphysical biology.

It might be instructive at this point to take a brief look at Aristotle, who is MacIntyre's main but by no means only source of inspiration. In The Nicomachean Ethics (1987) the good is defined as that at which all things aim. But ends are different, Aristotle says, some ends are activities and some ends are results beyond activities (Book 1, Ch. 1). The highest good is something final, something that is sought after for its own sake and not as a means to something else. This final good is happiness (Ch. 5). A good is then the telos of the activity, that for the sake of which we act.

Does this make MacIntyre's and Johnson's teleologies one of a kind? I am not sure. Johnson says that the practice of argumentation does not exist for itself, so that its "greater good" lies outside itself, namely in society at large. MacIntyre defines a practice as existing for its own sake, but locates practice as part of his account of the virtues, and this account is teleological. David Carr (2003) accuses MacIntyre of viewing (moral) virtues mainly as means to the pursuit of private and public goods. But a true virtue-ethical account, Carr claims, requires no personal or social reasons for aspiring to virtue; virtues are ends in themselves and their own reward. Furthermore, in his elaboration of a truly internal good, Carr says that,

As a teacher, I may recognise a need to be self-controlled and fair, and also that my pupils are more likely to become self-controlled and fair by my good example-but as a good teacher, I will aspire to become self-controlled and fair for its own sake irrespective of any possible benefit to others (2003, p. 261, emphasis original).

No doubt there are several things to be said about David Carr's views of virtues, ends and internal goods. I will make two observations. The first is that I do not think that Johnson would find this an adequate description of what he has in mind for the practice of argumentation. This would imply, for example, that a respondent should make his criticism of an argument for the criticism's own sake, irrespective of any possible benefit to the arguer (or anybody else). But Johnson defines criticism as reasoned evaluation of an argument that is communicated to the arguer, with the intention of helping to improve the product. The purpose of 


\section{Tone Kvernbekk}

criticism is to provide the arguer with constructive feedback, not the self-perfection of the respondent.

My second observation pertains to MacIntyre. Virtues are dispositions to act for the good, he says. Exercise of the virtues is not a means to the end of the good; rather exercise of the virtues is a necessary and central part of a good life, not a preparatory exercise to secure such a life. That is to say, his views are more subtle and sophisticated than Carr's portrayal would have it. Virtues are acquired in practice, but they are also necessary to achieve the internal goods, and the exercise of them is necessary to uphold and sustain not only the practice itself but the tradition within which the practice takes place.

According to Christopher Higgins (2003) we must distinguish between the telos of a practice and the literal aims pursued by the practitioners. The telos of a practice is a vision of the fully perfected work. It is in the light of that telos that we can evaluate the quality of actual achievements. And it is in striving to achieve this telos that the two kinds of goods are achieved: excellence of the product and the good of a certain kind of life. For MacIntyre, teleology may be more visible and important at the second stage of his development of the concept of virtue; the narrative unity of a human life. All lived narratives are teleological in character, he tells us, since they always embody some image of the future. And what is good for me? The ways I can live out that unity. The good life is spent in seeking for the good life, whether we name it happiness or something else, and the virtues are necessary for the seeking.

\section{Poiesis}

Admittedly, it may be hard to keep track of MacIntyre's treatment of virtues, excellences and internal goods. They sometimes seem to blend into each other. Moreover, it is not entirely clear at all times just how internal the internal goods are. In his treatment of the narrative order of human life, he says that without an overriding telos of life as a unity, our conception of certain virtues remains incomplete, since the content of a given virtue depends on how we rationally order goods in a hierarchy. And then he says, "unless there is a telos which transcends the limited goods of practices by constituting the good of a human life conceived as a unity, it will both be the case that a certain subversive arbitrariness will invade the moral life and that we shall be unable to specify the context of certain virtues adequately" (1996, p. 203). So there is a goodstranscending telos, but it operates at a different level, and I am not sure if it makes a difference for practice and my discussion of argumentation practice. 
MacIntyre clearly draws on Aristotle's distinction between praxis and poiesis, set forth in The Nicomachean Ethics (1987). Praxis, as alluded to above, is an activity where the end lies in the activity itself, and poiesis is an activity where the end is separable and lies outside the activity. For some reason, MacIntyre omits any mention of this distinction, despite the fact that his concept of practice is so clearly indebted to the Aristotelian praxis. As some of his critics have pointed out, MacIntyre classifies as practices what Aristotle would classify as examples of poiesis, e.g., architecture (e.g., Noddings 2003). But is architecture done for its own sake? Is not rather the end of architecture the buildings that are produced and their subsequent use? Aristotle organizes poiesis activities into a hierarchy. Leather is made for the harness-maker, who in turn makes bridles for the military, who in turn devises some military strategy, the end of which is victory. And the military concerns are the most important ones:

But in all these cases the ends of the architectonic arts or sciences, whatever they may be, are more desirable than those of the subordinate arts or sciences, as it is for the sake of the former that the latter are themselves sought after (Bk. 1, Ch. 1).

Could not argumentation conceivably be placed in such a hierarchy? Is the "good" in a good argument specifiable by arguer and critic exclusively, completely without reference to the possible goods of other practices? Or should the matter or the purpose in which the argument is part, also be taken into consideration? For example, politicians making a decision? The point is that argumentation serves a number of other practices, activities or domains-exactly what Johnson says that it does. But that would make it poiesis, not praxis.

Let me make a brief detour here and take a quick look at teaching again. Aristotle's distinction and its MacIntyrean version have had a great impact on much educational thinking. Wilfred Carr (1995) is adamant that teaching is praxis, an activity to realize some morally worthwhile good; its end only existing in the activity itself. Poiesis, Carr claims, is a species of rule-following action; its point is to bring some specific product or artifact into existence. Poiesis is guided by techne, which is a non-reflective know-how, whereas praxis is a form of reflective action, which can itself transform the theory that guides it (called phronesis, practical wisdom). With these descriptions of praxis and poiesis it is no wonder that Carr classifies teaching (or rather education) as praxis. But it is by no means evident that Aristotle's writings justify the description of poiesis as rule-following action and techne as non- 


\section{Tone Kvernbekk}

reflective know-how, and furthermore, the distinction itself may not be quite as clear-cut as Carr would have it.

David Miller (1994) takes issue with MacIntyre's neglect of the Aristotelian praxis-poiesis distinction, but turns it into a different point. Miller makes a distinction within the concept of practice: self-contained practice and purposive practice. Selfcontained practices are those where the whole point of the activity consists in internal goods and their achievements, and purposive practices exist to serve some end beyond themselves. There is nothing to prevent a purposive practice from having internal goods, from being a coherent and complex form of socially established human activity, from having a long history, from being an arena where the virtues flourish, from having standards of excellence and still have some end beyond itself. Miller's own favorite example is medicine. A physician may satisfy all standards of excellence and have access to all internal goods of the medical profession, but it will not amount to very much if his patients do not get well. We do not praise a surgeon, Miller observes, whatever remarkable skills he possesses or whatever efficient procedures he introduces, if the death rate from his operations is much higher than average.

MacIntyre writes as if all practices are self-contained rather than purposive. This, as Richard Smith (2003) points out, has the effect that his concept of practice does not do justice to whatever element of purposiveness might be found in the activity in question. This in turn, Smith says, leads to an even more serious problem: "Without the element of purposiveness it is difficult to see what prevents a practice from falling into self-indulgence and self-absorption, from coming to resemble in this respect an endlessly sophisticated tea-ritual” (p. 315). Whereas Wilfred Carr makes phronesis the only acceptable form of knowledge for teachers and educators, Smith speculates that self-absorption and descent into virtuosity (meaning excessive attention to one's own skills and knowledge) are constant risks for activities that are guided precisely by phronesis. And this is evidently not what Johnson wants for the practice of argumentation.

A categorization of argumentation practice as a purposive practice could help us avoid the dangers of self-indulgence and self-perfection and yet allow us to keep a notion of internal goods. I see no reason why the idea of internal goods should be rejected even if we give up argumentation as a practice in MacIntyre's sense. Johnson, I believe, would agree to this; he has after all told us what he thinks the internal goods of argumentation are or can be. It is worth noting that for teaching, an adoption of Miller's concept of purposive practice would profoundly change the discussion, since the contrast between teaching as an end in itself and teaching 
as a means to something else would disappear. It becomes possible for teaching to be both.

In self-contained practices, internal and external goods are easily kept apart since an internal good is only specifiable in terms of the practice itself and an external good, such as fame or money, is independent. For purposive practices, however, things are more complicated. External goods are still independent, but, as Miller maintains, internal goods are no longer specifiable exclusively in terms of the practice, but also in terms of the larger purpose that the practice serves. As we have seen, MacIntyre holds that internal goods are accessible only by participation and that only participants are competent judges of excellences, performances and internal goods. In a purposive practice such exclusiveness cannot be upheld. A critical review or evaluation of the practice in question can of course be conducted by its "insiders" from within the practice, but also, Miller says, by others in the light of the practice's larger cultural or societal purpose and function. It is clear to me that this is a concept of practice that fits the property of teleology much better than does MacIntyre's concept. Johnson explicitly states that argumentation exists not for itself, but rather for its cultural importance and the value of its products for society.

Finally, Miller argues that the slightly more "external" character of the internal goods necessitates a re-thinking of the virtues. They can, he says, no longer be viewed as self-sufficient. Virtues relevant to purposive practices also take on a more "external" character since they at least in part will be dependent on the needs and purposes of a larger society.

\section{Conclusion}

So far my discussion has concentrated exclusively upon one of Ralph Johnson's three properties of argumentation practice, namely teleology. What of the other two; dialectics and manifest rationality? No doubt they could merit discussion in themselves, but for my purposes here it has seemed more fruitful to focus on teleology, for the simple reason that I think it is that particular property which makes MacIntyre's concept of practice unsuitable as a concept of practice of argumentation, at least in Johnson's description of it.

MacIntyre says nothing about manifest rationality. But he writes much about rationality; for example in his discussion of the notion of an educated public, where the members share standards of argument and are thereby able to engage in productive rational debate. I see no reason why his concept of practice should not be able to accommodate manifest rationality. It may even be construed as a virtue? After all, he says that the virtues justice, courage and 
honesty have to be accepted as necessary components of any practice; every practice requires a certain kind of relationship between the participants. This, we might surmise, would hold also for a purposive practice.

MacIntyre's emphasis on the relationship between participants makes me think that also dialectics can be accommodated by his concept of practice. For Johnson, dialectics is a dynamic component of argumentation; it entails an exchange between arguer and critic. That is, there are two different roles involved. MacIntyre, to the best of my knowledge, does not address the issue of participants in a practice occupying different roles. Indeed, a painter may conceivably operate on his own, alone in his own studio; albeit not in complete isolation from other painters. A chess player (chess is another of MacIntyre's favorite examples of practice) does not operate on his own, but the relationship between two chess players is not parallel to that between an arguer and a critic. However that may be, he does speak about the relationship between practitioners and I do not see why dialectics cannot be accommodated.

But all in all Johnson's argumentation practice is purposive, whereas MacIntyre's practice is self-contained and inward-looking. My overall conclusion is that whereas 'practice', in all its complexity, may capture much of Johnson's conception of the practice of argumentation, it does not accommodate all three features. The practice of argumentation does not, so to speak, fall under MacIntyre's concept of practice. And where does that leave the practice of argumentation? None of what I have said touches on the acceptability of Johnson's notion of argumentation practice, unless one is prepared to argue that it should fit MacIntyre's concept. But I, for one, am not. The lack of fit is not a problem for the practice of argumentation; the problem is rather MacIntyre's concept of practice. Argumentation should not aspire to be a practice in MacIntyre's sense of the word. If a robust concept of practice is needed for Johnson's overall pragmatic theory, and I indeed believe it is, I would suggest that Miller's concept of a purposive practice is more promising than the Aristotelian concept of poiesis. Purposive practice, as I understand it, encompasses all that a 'practice' encompasses, plus the idea of an end beyond itself. Poiesis is bound by its opposition to praxis and has too much of an either/or character to be useful.

Does anything hang on argumentation being a 'practice' or a 'purposive practice'? Generally I would say that, yes, it makes a difference which concept of practice we adopt and employ and hopefully my analysis shows as much. It has certainly mattered much to some educationalists to classify teaching as a practice in MacIntyre's sense. And what the concept of purposive practice may give, I suggest, is a complex notion that can do four related 
things for us. It can serve as a reminder of the complexity and plurality of the activity; it can serve as a reminder of the long history and tradition that our argumentative deliberations have; it can serve as a reminder that argumentation activities have ends beyond themselves; and it can serve as a vaccination against narrow focuses on parts of the activity being taken for the whole enterprise.

Acknowledgements: I would like to thank Ralph Johnson for helpful comments on an earlier draft of this paper.

\section{References}

Aristotle (1987). The Nicomachean Ethics. Buffalo: Prometheus Books. Translated by J.

E.C. Welldon.

Carr, D. (2003). Rival conceptions of practice in education and teaching. Journal of

Philosophy of Education, 37, 2, 253-266

Carr, W. (1995). For Education. Towards critical educational inquiry. Buckingham: Open University Press.

Dunne, J. (2003). Arguing for teaching as a practice: A reply to Alasdair MacIntyre.

Journal of Philosophy of Education, 37, 2, 353-369.

Higgins, C. (2003). MacIntyre's moral theory and the possibility of an aretaic ethics

of teaching'. Journal of Philosophy of Education, 37, 2, 279-292.

Hitchcock, D. (2002). The practice of argumentative discussion. Argumentation, 16, 3, 287-298.

Hogan, P. (2003). Teaching and learning as a way of life. Journal of Philosophy of

Education, 37, 2, 207-224.

Johnson, R. H. (2000). Manifest rationality. A pragmatic theory of argument. Mahwah, NJ: Lawrence Erlbaum Associates.

MacIntyre, A. C. (1996). After virtue. A study in moral theory, $2^{\text {nd }}$ edition. London: Duckworth.

MacIntyre, A. C. and J. Dunne (2002). Alasdair MacIntyre on education: In dialogue

with Joseph Dunne. Journal of Philosophy of Education, $36,1,1-19$

Miller, D. (1994). Virtues, practices, and justice. In J. Horton and S. Mendus (eds), After MacIntyre: Critical perspectives on the work of Alasdair MacIntyre (p p. 245-264). Cambridge: Polity Press. 
278 Tone Kvernbekk

Noddings, N. (2003). Is teaching a practice? Journal of Philosophy of Education, 37, 2, 241-252.

Smith, R. (2003). Thinking with each other: The peculiar practice of the university. Journal of Philosophy of Education, 37, 2, 309-324.

Wain, K. (2003). MacIntyre: Teaching, politics and practice. Journal of Philosophy of Education, 37, 2, 225-240. 